\title{
Simultanious Determination of Related Organic Impurities of Ibuprofen and Paracetamol in Combination Solid Dosage Form by Rp-hplc With Qbd Approach
}

\author{
PALAKURTHI ASHOK KUMAR ${ }^{1}$, DONGALA THIRUPATHI ${ }^{1}$, \\ Y. RAVINDRA KUMAR ${ }^{1}$ and ANIREDDY JAYASHREE ${ }^{2 *}$ \\ ${ }^{1}$ Analytical Research \& Development, Dr.Reddy's Laboratories, IPDO, Bachupally, \\ Hyderabad-500072,India. \\ ${ }^{2}$ Center for Chemical Sciences and Technology Institute of Science \& Technology Jawaharlal \\ Nehru Technological University, Kukatpally, Hyderabad -500 085, India. \\ *Corresponding Author: Email:ashokchem2000@gmail.com
}

http://dx.doi.org/10.13005/ojc/330349

(Received: October 01, 2016; Accepted: February 02, 2017)

\begin{abstract}
A stability indicating $Q b D$ based gradient method was developed and validated with the concept of quality by design $(\mathrm{QbD})$ and with help of design of experiments (DoE) tool for the simultaneous determination of related organic impurities of Ibuprofen and Paracetamol in a combination solid oral dosage form by reverse phase high performance liquid chromatography (RP-HPLC). The most important critical quality attributes (CQA) of the developed test method were chosen and were evaluated by using "Design-Expert@ 8" software tool with a quadratic mode of central composite design (CCD). The separation between all known impurities was achieved using "X-Terra RP18, 250-mm × 4.6- $\mathrm{mm}, 5-\mu \mathrm{m}$ column with a $1.0 \mathrm{~mL} / \mathrm{min}$ flow rate of gradient elution. The UV detection wavelength was used as $220 \mathrm{~nm}$. The method validation is carried out as per ICH guidance, and the parameters include precision, accuracy, specificity, linearity, detection limit (DL), quantitation limit $(\mathrm{QL})$, and robustness.
\end{abstract}

Keywords: Paracetamol, QbD, Design of Experiments

\section{INTRODUCTION}

Ibuprofen [(RS)-2-(4-(2-Methylpropyl) phenyl) propanoic acid] and Paracetamol [N-(4hydroxyphenyl) ethanamide] are often sold in a form of combination oral dosage. The recommended dose of Ibuprofen is $1200 \mathrm{mg} /$ day and Paracetamol is $4000 \mathrm{mg} /$ day. Ibuprofen is category of non-steroidal anti-inflammatory drug (NSAID) which can be used to relief a pain, fever and inflammation. And Paracetamol is a generally used medicine to treat a pain and fever. 
In current USP, no official monograph is available for Ibuprofen and Paracetamol, but only the limit test for limit of ibuprofen related compound $\mathrm{C}$ are reported for Ibuprofen tablets, UPS 39, page 4269 and Ibuprofen API, USP 39, page 4267'-2. As per literature there are several assay methods are reported for simultaneous determination of Ibuprofen and Paracetamol ${ }^{3}$. And a separate impurity methods are reported for Paracetamol ${ }^{4}$ and Ibuprofen ${ }^{5}$. But, no stability indicating method is reported for the simultaneous determination of related organic impurities of Ibuprofen and Paracetamol in a combinational dosage form with $\mathrm{QbD}$ approach.

Now-a-days, Quality-by-design (QbD) is become an important paradigm for the risk assessment of process R\&D (synthesis), formulation processes and analytical research of pharmaceutical industry majorly. The concept of $\mathrm{QbD}$ (DOE) is recommended by $\mathrm{ICH}, \mathrm{Q} 8$ (R2) guidance. The definition of $\mathrm{QbD}$ is as follows, "A systematic approach to development that begins with redefined objectives and emphasizes product and process understanding and process control, based on sound science and quality risk management" ${ }^{6-11}$.

In accordance to U.S FDA requirement from 2013, MODR needs to be conducted together with method validation. But, a conference on "A QbD by U.S FDA in 2014", the current (OFAT) approach in method development phase is not an appropriate method approach for routine analysis to be considered under regulatory flexibility ${ }^{12-13}$. The information which is specified in available literature papers was referred for guidance ${ }^{14-16}$ and to investigate the impact of different variables on resolution (as method response) and to verify method performances.<smiles>CC(C)Cc1ccc(C(C)C(=O)O)cc1</smiles>

Fig. 1: Chemical Structure of Ibuprofen<smiles>CC(=O)Nc1ccc(O)cc1</smiles>

Fig. 2: Chemical Structure of Paracetamol
The aim of current research work is to develop and validate a stability indicating method for the simultaneous determination of organic impurities in Ibuclin Tablets for (Ibuprofen and Paracetamol, $100 \mathrm{mg} / 125 \mathrm{mg}$ ) by Quality by Design (QbD) approach.

\section{MATERIALS AND METHODS}

\section{Chemicals}

Ibuprofen Standard, Paracetamol Standard and Ibuclin tablets (Ibuprofen and Paracetamol, $100 \mathrm{mg} / 125 \mathrm{mg}$ ) were supplied by Dr. Reddy's laboratories limited, Hyderabad, India. Acetonitrile (HPLC grade), methanol (HPLC grade), and ortho phosphoric acid $\left(\mathrm{H}_{3} \mathrm{PO}_{4}, \mathrm{AR}\right.$ grade) were purchased from Merck, Darmstadt, Germany. The purified water (HPLC grade) was collected from Milli-Q Plus water purification system which is manufactured by Millipore.

\section{Chromatographic Parameters}

The chromatographic analysis was carried out on a Waters Alliance HPLC with a photodiode array detector. The output signal was recorded using Empower 2 Software. The column was used as "X-Terra RP18, $250 \mathrm{~mm}$ x $4.6 \mathrm{~mm}, 5 \mu \mathrm{m}$ (Waters, USA)". The separation was achieved using a gradient method elution. Mobile phase A was contained a mixture of $\mathrm{pH} 2.5$ buffer solution (purified water $\mathrm{pH}$ adjusted to 2.5 with ortho phosphoric acid) and methanol in the ratio of 950:50 $(\mathrm{v} / \mathrm{v})$ and mobile phase $\mathrm{B}$ contained a mixture of $\mathrm{pH} 2.5$ buffer solution, acetonitrile and methanol in ratio of 200:200:600 $(v / v / N)$. The flow rate of mobile phase was set as $1.0 \mathrm{~mL} / \mathrm{min}$. The gradient program was set as: time $(\mathrm{min}) / \%$ mobile phase B: $0.0 / 5,5 / 5,20 / 50$, 40/50, 55/70, 85/70, 86/5, and 100/5. The column temperature was maintained at $25^{\circ} \mathrm{C}$ and the detection was monitored at a wavelength of $220 \mathrm{~nm}$. The injection volume was $10.0 \mathrm{~mL}$. The diluent was a solution of ph 2.5 buffer solutions and acetonitrile in the ratio of 50:50 $(\mathrm{v} / \mathrm{v})$. All sample solutions were centrifuged by using the centrifuge: REMI R-8C BL. Design-Expert 8 software was used for to design the current research work.

\section{Preparation of Test Solutions}

The sample solution was prepared with a concentration of $1000 \mu \mathrm{g} / \mathrm{mL}$ of Ibuprofen, and the 
spiked sample solution is prepared by spiking all known impurities (11 impurities) at the concentration of $0.2 \%$ with respect to respective sample solution on a sample solution which had a concentration of $1000 \mu \mathrm{g} / \mathrm{mL}$ of Ibuprofen and $1250 \mu \mathrm{g} / \mathrm{mL}$ of Paracetamol. The placebo solution was prepared same as sample solution.

\section{Method Development and Optimization Selection of Detector and Wavelength}

An individual stock solution of lbuprofen and Paracetamol API and its impurities were prepared in diluent and scanned using a photodiode array detector (PDA) in the range of $200 \mathrm{~nm} \sim 400 \mathrm{~nm}$. The spectra of each component was verified, and found that all the impurities showing absorbance maximum at about $220 \mathrm{~nm}$. Hence, $220 \mathrm{~nm}$ was selected for method detection.

\section{Finalization of Sample Concentration and Method Optimization}

Initial chromatographic conditions selected for method are reversed-phase HPLC with X-Terra $\mathrm{RP} 18,150 \mathrm{~mm} \times 4.6 \mathrm{~mm}$, 5-ìm column with isocratic flow. The mobile phase is mixture of $\mathrm{pH} 3.0$ buffer and acetonitrile $(70: 30(\mathrm{v} / \mathrm{v}))$. The flow rate is $1.0 \mathrm{~mL} / \mathrm{min}$ and the CTO is at $25^{\circ} \mathrm{C}$. With the above conditions paracetamol and its impurities eluted below $1 \mathrm{~min}$ RT and resolution between Ibuprofen impurities is not good. To meet resolution criteria between the closely eluting peaks, the buffer concentration was increased to $70 \%$, even though resolution between peaks found to be below 2.0.

Due to the inefficient nature of the isocratic mode, the gradient program was used to achieve the good separation, resolution $>2$, between all peaks, i.e 11 impurities and 2 active peaks. Separation tried with same column and with by varying $\mathrm{pH}$ of buffer $\mathrm{A}$ $\& B$, gradient program also changed to get resolution $(\mathrm{R})>2$. Finally, the optimized chromatographic condition were as mentioned in "Chromatographic Parameters" section .

All impurity peaks separated with $(R)>2$ resolution. No interference was observed at Paracetamol, Ibuprofen and all impurities due to the blank (diluent) and other excipients (placebo) which are used in the tablets formulation. The typical chromatogram of all impurities spiked sample solution was shown in Figure 3.

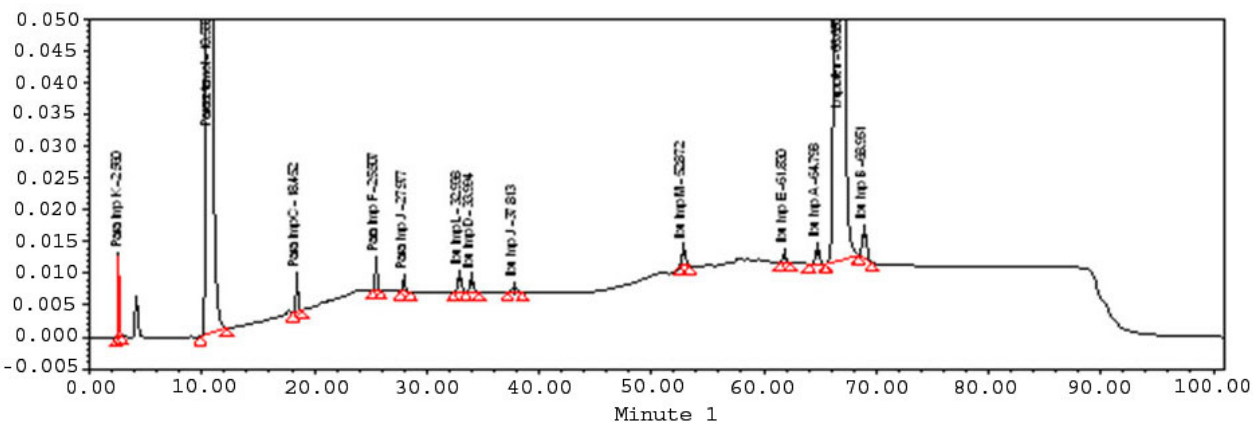

Fig. 3: Typical chromatogram of Impurities Spiked sample

Table 1. QbD tools identification in Analytical method Development

\begin{tabular}{llll}
\hline S No & QbD Tool & Analytical Method & RS \\
\hline 1 & $\begin{array}{l}\text { Quality Target Product } \\
\text { Profile(QTPP) }\end{array}$ & $\begin{array}{l}\text { Analytical Target } \\
\text { Profile(ATP) }\end{array}$ & $\begin{array}{l}\text { Accurate Quantification of impurities. } \\
\text { Common method. } \\
\end{array}$ \\
& Critical Quality Attributes & Critical Method & $\begin{array}{l}\text { Single sample preparation. } \\
\% \text { impurities. }\end{array}$ \\
& $($ CQA) & Attributes (CMA) & Resolution \\
3 & Critical Process parameters & Critical method & Flow. \\
& $($ CMP) & parameter (CMP) & Column temperature \\
& & & Integration of peaks \\
\hline
\end{tabular}




\section{Experimental Design For Qbd Study Quality by Design}

A $\mathrm{QbD}$ has different tools such as, (1) Analytical Target Profile (ATP), (2) Critical Quality Attributes (CQA), (3) Risk assessment, (4) Method Optimization and Development with DoE, (5) MODR (Method Operable Design Region), (6) Control Strategy and Risk assessment, (7) Analytical QbD Method Validation and (8) Continuous Method Monitoring. The pharmaceutical QbD is a systematic approach for analytical method development, to begins with tentative method conditions to achieve operating ranges. A broad knowledge obtained from the $\mathrm{QbD}$ process is used to establish a method operable design region (MODR). Analytical method development tools are identified and tabulated in Table 1.

\section{Selection of Factors and Responses}

The method variables are evaluated and listed as follows: (1) flow rate of mobile phase: $0.5 \mathrm{~mL} / \mathrm{min}$, and $1.5 \mathrm{~mL} / \mathrm{min}$ and (2) column temperature: $25^{\circ} \mathrm{C}$ and $35^{\circ} \mathrm{C}$ which given in Table 2.
The resolution between (1) Impurity $D$ \& Impurity L, (2) Impurity A \& Ibuprofen, and (3) Ibuprofen \& impurity B was used as a response in experimental design as controlling response, which is expected to affect and control method responses.

The critical method parameters (CMP) and method attributes are identified from the RA and set low and high factor limits for experimentation along with acceptance limits for attributes. Three responses are evaluated; $R 1, R 2$ and $R 3$. $R 1$ is the resolution between Ibuprofen impurity-D and Impurity-L, R2 is the resolution between Ibuprofen impurity- $A$ and Ibuprofen and $R 3$ is the resolution between Ibuprofen and Ibuprofen impurity-b. The factors are presented in Table 2.

\section{Selection of DOE and Design Layout}

The present research work was designed with help of "Design-Expert $₫$ 8" software tool with a quadratic mode of central composite design (CCD), $\left(3^{n-1}=13\right.$ runs with 2 factors $)$ to identify the optimum conditions for separation of impurities of ibuprofen during method development. This factorial design can
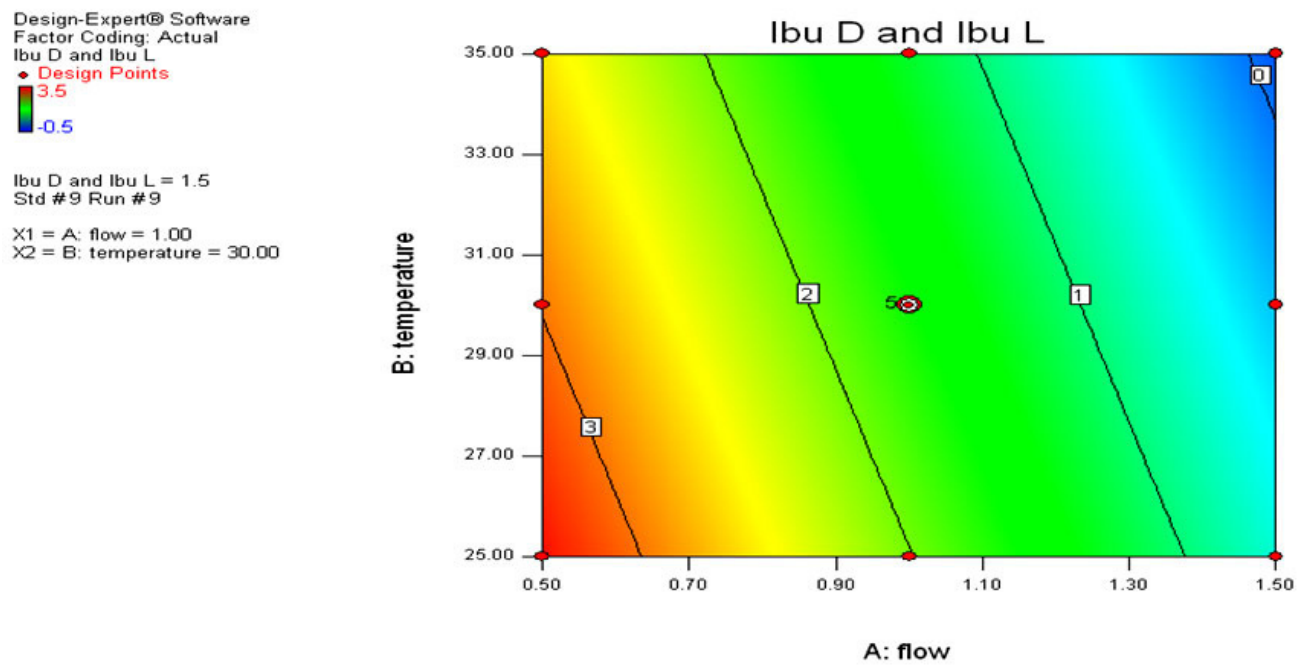

Fig. 4: Contour plot of resolution between lbuprofen impurity D \& Ibuprofen impurity L

Table 2. CMPs and Levels

\begin{tabular}{lccc}
\hline $\begin{array}{l}\text { Name of } \\
\text { Condition }\end{array}$ & Low Condition & Original Condition & High Factor \\
\hline Flow rate $(\mathrm{mL} / \mathrm{min})$ & 0.5 & 1.0 & 1.5 \\
Column Temperature $\left({ }^{\circ} \mathrm{C}\right)$ & 25 & 30 & 35 \\
\hline
\end{tabular}


give full evaluation of individual impurities resolutions. The experimental observations along with Factorial Design (DoE) plan and the statistical analysis is given is shown in Table 2. The MODR (Method Operable Design Region) was defined using all variables. From MODR suitable method conditions were selected and subjected to verification for method performance like accuracy and precision (NLT 2 resolution) and robustness as targeted response.

\section{RESULTS AND DISCUSSION}

The quantitative determination of organic impurities in a combination drug product with a shorter run time and with a stability indicating characteristics is a critical task for analytical scientist(s). However, we have been taken it as a challenge and was developed a single testing method for separation of 13 active peaks (11 known impurity peaks and 2 active peaks), see Fig. 3 .

\section{DOE - Statistical Response Analysis}

Each of responses was analyzed using

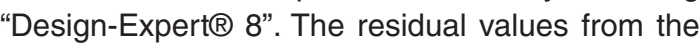
corresponding Diagnostics for each response are presented in Table 3.

The method assessment for attaining CQA of the product is shown in Table 2. To initiate the

Table 3: CMPs and Statistical Responses

\begin{tabular}{|c|c|c|c|c|c|c|}
\hline Std & Run & $\begin{array}{l}\text { Factor } 1 \\
\text { A: flow }\end{array}$ & $\begin{array}{c}\text { Factor } 2 \\
\text { B:temperature }\end{array}$ & $\begin{array}{c}\text { Response } 1 \\
\text { bu } D \text { and lbu L } \\
\text { resolution }\end{array}$ & $\begin{array}{c}\text { Response } 2 \\
\text { lbu A and lbu } \\
\text { resolution }\end{array}$ & $\begin{array}{c}\text { Response } 3 \\
\text { Ibu and lbu } \mathrm{B} \\
\text { resolultion }\end{array}$ \\
\hline 8 & 1 & 1.00 & 35.00 & 1.6 & 2.9 & 3.2 \\
\hline 13 & 2 & 1.00 & 30.00 & 1.5 & 2.7 & 3.3 \\
\hline 3 & 3 & 0.50 & 35.00 & 2.5 & 2.8 & 3.4 \\
\hline 6 & 4 & 1.50 & 30.00 & 0 & 2.8 & 3.3 \\
\hline 10 & 5 & 1.00 & 30.00 & 1.5 & 2.7 & 3.3 \\
\hline 1 & 6 & 0.50 & 25.00 & 3.5 & 2.8 & 2.9 \\
\hline 7 & 7 & 1.00 & 25.00 & 1.8 & 2.7 & 3.2 \\
\hline 5 & 8 & 0.50 & 30.00 & 3.2 & 2.8 & 3.4 \\
\hline 9 & 9 & 1.00 & 30.00 & 1.5 & 2.7 & 3.3 \\
\hline 2 & 10 & 1.50 & 25.00 & 1.1 & 2.7 & 3.3 \\
\hline 12 & 11 & 1.00 & 30.00 & 1.5 & 2.7 & 3.3 \\
\hline 11 & 12 & 1.00 & 30.00 & 1.5 & 2.7 & 3.3 \\
\hline 4 & 13 & 1.50 & 35.00 & 0 & 2.8 & 3.3 \\
\hline
\end{tabular}

Design-Expert] Software Factor Coding: Actual - Design Points 2.62

Ibu $A$ and lbu $=2.7$
Std $\# 9$ Run $\# 9$ $\times 1=$ A: flow $=1.00$

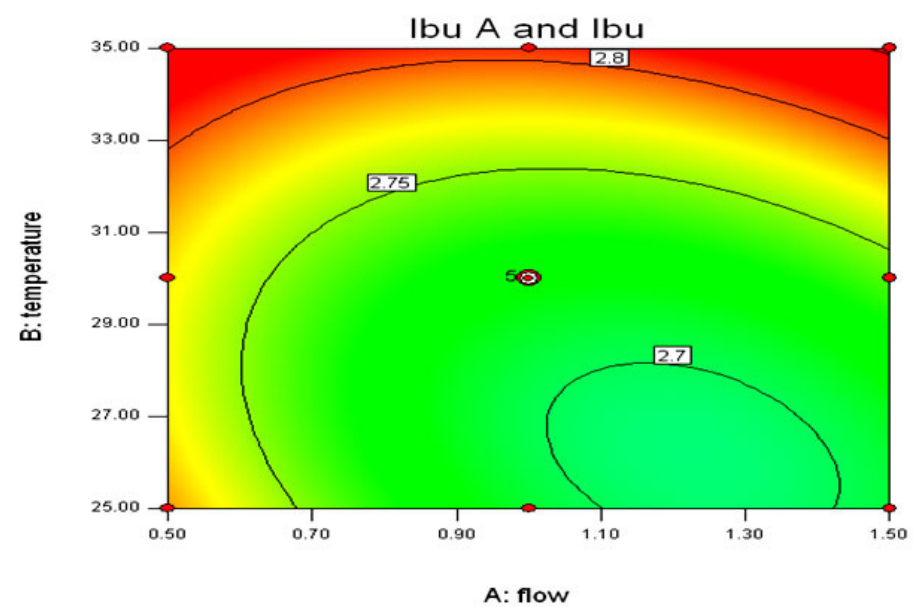

A: flow

Fig. 5: Contour plot of resolution between Ibuprofen impurity A \& Ibuprofen 
QbD work, resolution between Ibuprofen impurity A and Ibuprofen were considered in the selection of input variables for factorial design $\left(2^{n-1}\right)$. Mid points were added to find the curvature effect. Once the curvature effect was significant, CCD was adopted to get response surface to optimize design. C18 column was chosen as stationary phase due to wide acceptability pharmaceuticals and high reproducibility. In initial run, $70 \%$ buffer was used for retaining paracetamol and its impurities. Column temperature, Buffer, methanol components were considered as qualitative variable in water and were controlled.

In order to achieve the complete scientific understanding between method results and input variables, a central composite design was designed and performed. The various variables and their levels were shown in Table 2. The obtained experimental results was subjected various statistical parameter for better understanding and was found to be a nonlinear relationship between input variable and response. The statistical data analysis is shown in Fig. 4, Fig. 5 and Fig. 6.

The resolution between Impurity-D and Impurity- $L$ is sensitive towards high flow rate and high column temperature. The resolution between Impurity-A and Ibuprofen is independent of flow and column temperature variations. The resolution between Impurity-B and Ibuprofen is independent of flow and column temperature variations. The proposed analytical parameters are suitable to work at desired efficiency with allowable practical variations in day to day operations.

\section{METHOD VALIDATION}

Validation of method performed as per ICH guidelines $^{20}$.

\section{System Suitability}

Diluted standard (prepared at $2 \mathrm{ppm}$ of Ibuprofen \& 2.5 ppm of paracetamol in diluent), and resolution solution (prepared with 2 ppm of Ibuprofen impurity A \& 1000 ppm of Ibuprofen) were injected as part of system suitability and all the system suitability parameters like standards tailing factor, plate counts, $\%$ RSD for average areas of standard peaks and resolution between Impurity A \& Ibu are found to be within the acceptable criteria.

\section{Specificity}

To know the method capability, intrinsic stability of the molecules and separation of Impurites in the method performed force degradation studies on the sample with a concentration 1000 ppm of Ibuprofen and 1250 ppm of Paracetamol, on Active pharmaceutical ingredient. Performed forced degradation study on final finished product formulations to know the placebo peaks interference with known impurities and formation of new impurities in the final formula. Taken tablets on to a mortar vessel crushed in to fine powder and prepared sample. The degradation performed in Hydrolytic condition, Oxidative condition, Thermolytic condition and Photolytic conditions.
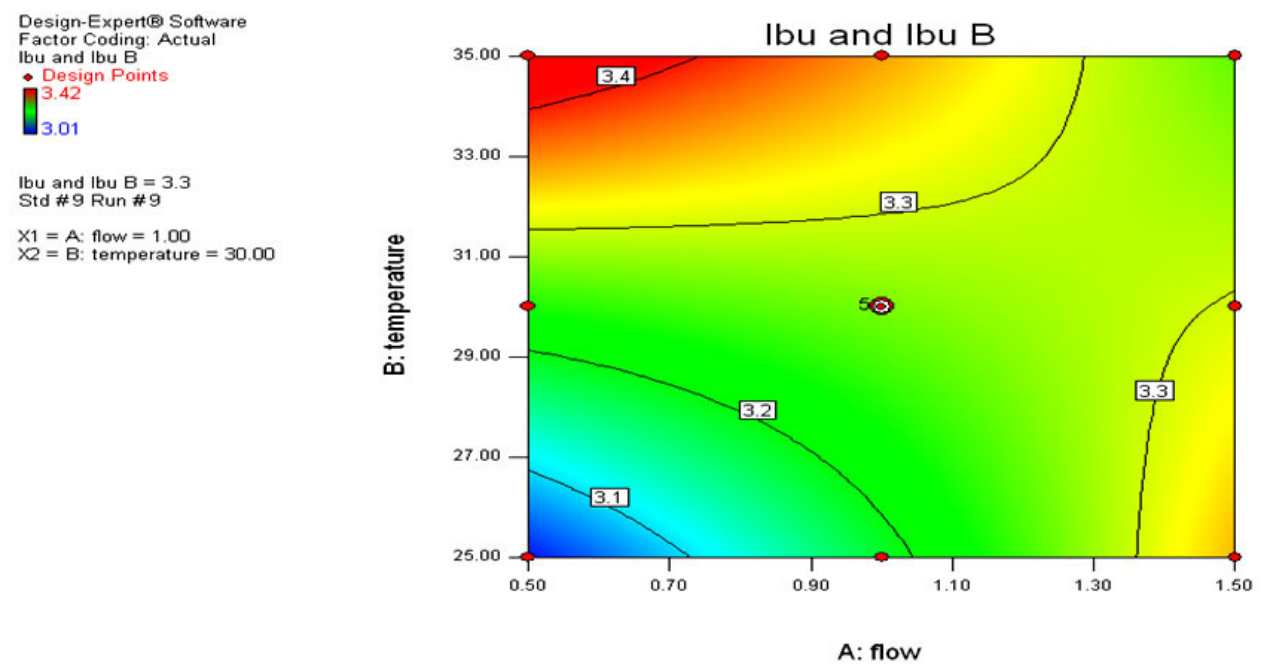

Fig. 6: Contour plot of resolution between Ibuprofen \& Ibuprofen impurity B 
In the Hydrolytic condition Sample Exposed to acid and Base conditions. For acid condition sample was treated with Hydrochloric acid with concertation of $0.1 \mathrm{~N} \quad(0.1 \mathrm{~N} \mathrm{HCl})$ at $60^{\circ} \mathrm{C}$ for about $30 \mathrm{~min}$, for base sample was treated with concertation of $0.1 \mathrm{~N}$ sodium hydroxide at $60^{\circ} \mathrm{C}$ for about $10 \mathrm{~min}$. and for Humidity condition sample exposed to $90 \% \mathrm{RH}$ for about 7 days.

In the Oxidative condition sample was exposed to $5 \%$ hydrogen peroxide for about $2 \mathrm{hrs}$ at $60^{\circ} \mathrm{C}$ and Thermal condition sample exposed to $105^{\circ} \mathrm{C}$ for about 3hours finally the Photolytic codtions sample exposed to 1.2 million lux hours followed by 200 watt hours-m ${ }^{-2}$ UV and visible light.

\section{Precision}

The precision was performed by preparing six individual sample solutions as per the test method and spiked the Impurites with a concentration of $0.2 \%$ then injected in to HPLC and calculated \% of each individual impurity the \% RSD of six sample solutions. The ruggedness (intermediate precision) of the method was also evaluated using different analysts and a different instrument in the same laboratory on a different day. Also, the precision and intermediate precision study was performed for unknown impurity by spiking $2.0 \mu \mathrm{g} / \mathrm{mL}$ of Ibuprofen and $2.5 \mu \mathrm{g} / \mathrm{mL}$ of Paracetamol on the placebo as per test preparation.

\section{Accuracy}

The accuracy of the method was demonstrated at five different concentration levels by preparing each level in triplicate preparations. The analysis was carried out by spiking all of the impurities on the Finished product sample at $0.1 \%, 0.2 \%, 0.5 \%, 0.75 \%$, and $1.0 \%$ of the test concentration $(1000 \mu \mathrm{g} / \mathrm{mL}$ of Ibuprofen \& $1250 \mu \mathrm{g} / \mathrm{mL}$ of Paracetamol ). Also, the accuracy study was performed for unknown impurities by spiking both the APIs on the placebo at the abovementioned levels. The percentage mean recoveries at each level for all of the impurities, Paracetamol and Ibuprofen were calculated.

\section{Detection Limit (DL) and Quantitation Limit} (QL)

To demonstrate the sensitivity of the method Established The DL and QL for all known impurities and both APIs by using the signal to noise ratio method and the values are $\mathrm{S} / \mathrm{N}$ of $3: 1$ and $10: 1$, respectively, To prove the repeatability of the method at QL level prepared six samples preparation as per the test method and spiked the impurities at QL level and injected in to the HPLC. Then calculate the \% $\mathrm{RSD}$ and recovery of Impurites at QL concentrations. In the same way by spiking both the APIs on the placebo at the above-mentioned levels performed precision and accuracy and calculated the \% RSD and recovery of APIs at QL concentrations

\section{Linearity}

To demonstrate the Linearity of the method and detector response prepared linearity of solutions of Impurites and APIS from the LOQ level to 1.0\% of the test concentration (six different levels are prepared) and injected in to the HPLC as per the test method conditions. Calculated the linearity of test method by taking, The peak area versus concentration of each level data were subjected to least-squares linear regression analysis. The calibration curve was drawn by plotting impurity areas against the concentration expressed in $\mu \mathrm{g} / \mathrm{mL}$.

\section{Robustness}

To prove the robustness of the method deliberately changed the chromatographic conditions from as such method to lower side and higher side (flow rate and column temperature), and injected the sample solutions. Observed the system suitability results in all conditions. All peaks are (impurity peaks and active peaks) were adequately resolved and elution orders remained unchanged. The resolutions between adjacent peaks were found to be satisfactory, see Table 3 .

\section{CONCLUSION}

Analytical method development and validation by the $\mathrm{QbD}$ approach was played a key role in the quantitative determination of organic impurities of Ibuprofen and Paracetamol and to ensuring the product quality. The outcome of the $\mathrm{QbD}$ is the understanding from product development to commercial production. Scientist can easily identify the risk initially so that quality can be increased. The gradient HPLC method developed for the determination of Ibuprofen and paracetamol 
impurities in pharmaceutical combination dosage form was found to be specific, precise, linear, accurate, and robust. The developed method can be used for the stability analysis of formulated samples.

\section{ACKNOWLEDGEMENTS}

The author wish to thank the management of Dr. Reddy's Laboratories Limited, Hyderabad, India.

\section{REFERENCES}

1. United States Pharmacopeia monograph, Ibuprofen API, USP 39. 2016, 4267.

2. United States Pharmacopeia, Ibuprofen Tablets, USP 39. 2016, 4269.

3. Prasanna Reddy Battu, MS Reddy. RP-HPLC Method for Simultaneous Estimation of Paracetamol and Ibuprofen in Tabets. Asian $J$ Research Chem. 2009, 2: 70-72.

4. Rao RN, Narasaraju A. Rapid separation and determination of process-related substances of paracetamol using reversed-phase HPLC with photo diode array as a detector. Anal Sci. 2006, 22: 287-292.

5. Cafiglioli G, Valeraia P, Brunella P, Sergio C, Attilia $A$, et al. Identification of degradation products of Ibuprofen arising from oxidative and thermal treatments. J Pharm Biomed Anal. 2002, 30: 499-509.

6. International Conference on Harmonization of technical requirements for registration of pharmaceuticals for human use, ICH harmonized tripartite guideline, Draft Step 4. Pharmaceutical Development Q8 (R1). 2008.

7. Yu L. Pharmaceutical quality by design: Product and process development, understanding and control. Pharm Res. 2008, 25:781-791.

8. Lee SL, Raw AS, Yu L. Significance of drug substance physiochemical properties in regulatory quality by design. In Drugs and the Pharmaceutical Sciences 78 (Preformulation in Solid Dosage Form Development), London: Informa Healthcare. 2008, 571-583.

9. Mhatre R, Rathore AS. Quality by design: An overview of the basic concepts. In Quality by design for biopharmaceuticals. New York: Wiley. 2009, 1-8.

10. International Conference on Harmonization (ICH). Tripartite Guidelines, ICH Q8 (R2): Pharmaceutical Development. 2009.

11. International Conference on Harmonization
(ICH). Tripartite Guidelines, ICH Q9: Quality Risk Management. 2006.

12. Chatterjee S. QbD Consideration for Analytical Methods - FDA Perspectives, US IFPAC Annual Meeting; Baltimore. 2013.

13. Alexander Schmidt $H$. Validation and Transfer, Berlin, 4th Annual Conference on Analytical Method Development, Germany. 2014.

14. Lewis GA, Mathieu D, Phan Tan L. New York: Marcel Dekker;. Pharmaceutical Experimental Design. 1999.

15. Wen-Ying $\mathrm{H}$, Pei-Chi L, Ling-Kuei H, Li-Ping L, Wayne CL. Stability studies of ascorbic acid 2-glucoside in cosmetic lotion using surface response methodology. Bioorg Med Chem Lett. 2013; 23:1583-7.

16. Srinubabu G, Raju CH, Sarath N, Kiran KumarP, Seshagiri Rao JV. Development and validation of a HPLC method for the determination of voriconazole in pharmaceutical formulation using an experimental design. Talanta. 2007,71,1424-9.

17. Orlandini S, Pinzauti S, Furlanetto S. Application of quality by design to the development of analytical separation methods. Anal Bioanal Chem. 2013,50,405:443.

18. Beg S, Sharma G, Katare OP, Lohan S, Singh B. Development and validation of stabilityindicating liquid chromatographic method for estimating olmesartan medoxomil using quality by design. J Chromatogr Sci. 2015, 53, 1048-59.

19. Kurmi M, Kumar S, Singh B, Singh S. Implementation of design of experiments for optimization of forced degradation conditions and development of a stability-indicating method for furosemide. J Pharm Biomed Anal. 2014, 96, 135-43.

20. $I C H-Q 2(R 1)$ Guideline on Validation of Analytical Procedure: Text and Methodology; 2005. 